Hidayat, et al/Jurnal Ekonomi Syariah Teori dan Terapan Vol. 6 No. 7 Juli 2019: 1462-1475; PENERAPAN PERILAKU KONSUMSI ISLAM PADA PENERIMA BEASISWA SATU KELUARGA SATU SARJANA BADAN AMIL ZAKAT NASIONAL DI JAWA TIMUR (PERSPEKTIF FAHIM KHAN)

\title{
PENERAPAN PERILAKU KONSUMSI ISLAM PADA PENERIMA BEASISWA SATU KELUARGA SATU SARJANA BADAN AMIL ZAKAT NASIONAL DI JAWA TIMUR (PERSPEKTIF FAHIM KHAN)'
}

\author{
Edwin Bahtiar Hidayat \\ Departemen Ekonomi Syariah - Fakultas Ekonomi dan Bisnis - Universitas Airlangga \\ Email: edwinbahtiar9@gmail.com \\ Eko Fajar Cahyono \\ Departemen Ekonomi Syariah - Fakultas Ekonomi dan Bisnis - Universitas Airlangga \\ Email: fajars2ei@gmail.com
}

\begin{abstract}
:
This research aims to know how application of Islamic Consumption Behavior Fahim Khan's Perspektive on Recipients Satu Keluarga Satu Sarjana Badan Amil Zakat Nasional (SKSS BAZNAS) Scholarship in East Java. This method that used is qualitative approach with $s$ case study strategy. Data was collected by interview dan direct observation of the object research. The analysis technique that used is descriptive qualitative analysis that is narrating the result of interview dan direct observation. Based on the result of this study concluded all recipient of Satu Keluarga Satu Sarjana Badan Amil Zakat Nasional (SKSS BAZNAS) scholarship in East Java have been applied Fahim Khan's perspective of Islamic consumption behavior. Suggestions for further research should apply this research to another scholarship deeply.
\end{abstract}

Keywords: Consumption Behavior, Fahim Khan, world consumption, hereafter consumption

\section{PENDAHULUAN}

\section{Latar Belakang}

Manusia diciptakan oleh Allah sebagai khalifah di bumi. Kata khalifah pada mulanya berarti yang menggantikan, atau yang datang sesudah siapa yang datang sebelumnya (Shihab, 2004:142). Sebagai khalifah di bumi, manusia diwajibkan untuk mengatur segalanya atas kehendak Allah. Allah membebaskan manusia bertindak apa saja asalkan tidak melanggar aturan yang sudah ditetapkan oleh Allah dalam AlQur'an dan Hadits. Sebagai khalifah, manusia haruslah mampu untuk memakmurkan bumi. Segala kegiatan yang dilakukan haruslah untuk mengatasi masalah dan memberikan kesejahteraan pada makhluk di bumi.
Manusia adalah makhluk yang sempurna diantara ciptaan Allah yang lain. Dengan kesempurnaan tersebut sehingga manusia memiliki kebutuhan dan keinginan yang beragam. Kebutuhan manusia adalah segala sesuatu yang diperlukan agar manusia berfungsi secara sempurna, berbeda dan lebih mulia daripada makhlukmakhluk lainnya (P3El, 2008:130). Secara garis besar, maka kebutuhan manusia itu dikelompokkan ke dalam dua kelompok besar, yaitu kebutuhan fisik atau kebutuhan badaniah, dan kebutuhan psikis atau kebutuhan kejiwaan (Rosyidi, 2005:49). Apabila kebutuhan manusia tidak terpenuhi maka akan menggangu kelangsungan hidup manusia. Sehingga diperlukan usahausaha yang harus dilakukan manusia agar dapat memenuhi kebutuhan hidupnya.

\footnotetext{
${ }^{1}$ Jurnal ini merupakan bagian dari skripsi Edwin Bahtiar Hidayat, NIM: 041311433133, yang diuji pada tanggal 16 April 2019.
} 
Hidayat, et al/Jurnal Ekonomi Syariah Teori dan Terapan Vol. 6 No. 7 Juli 2019: 1462-1475; PENERAPAN PERILAKU KONSUMSI ISLAM PADA PENERIMA BEASISWA SATU KELUARGA SATU SARJANA BADAN AMIL ZAKAT NASIONAL DI JAWA TIMUR (PERSPEKTIF FAHIM KHAN)

Berdasarkan intensitasnya, kebutuhan dibagi menjadi 3, yaitu: primer, sekunder, dan tersier. Sedangkan dalam islam kebutuhan dibagi menjadi 3, yaitu: dharuriyyat, hajyiyat, tahsiniyyat. Islam memandang bahwa dalam memenuhi kebutuhan manusia tidak boleh sembarangan, namun harus dengan cara-cara yang halal agar mendatangkan mashlahah dunia akhirat.

Secara umum perbedaan antar kebutuhan dan keinginan sebagai berikut:

Tabel 1.

Karakteristik Kebutuhan dan Keinginan

\begin{tabular}{|l|c|c|}
\hline Karakteristik & Keinginan & Kebutuhan \\
\hline Hasil & $\begin{array}{c}\text { Hasrat (nafsu) } \\
\text { manusia }\end{array}$ & Fitrah manusia \\
\hline Ukuran & Kepuasan & $\begin{array}{c}\text { Manfaat dan } \\
\text { berkah }\end{array}$ \\
\hline Sifat & Subjektif & Obungsi \\
\hline Tuntunan & Dibatasi/dikendalikan & Dipenuhi \\
Islam & \multicolumn{2}{|c|}{} \\
\hline \multicolumn{2}{|c|}{ Sumber: } & Pusat \\
\hline
\end{tabular}

Pengembangan Ekonomi Islam, 2008: 131

Ekonomi mikro menjelaskan how dan why sebuah pengambilan keputusan dalam setiap unit ekonomi (Karim, 2011). Bagaimana konsumen membuat keputusan dan pemilihan terhadap suatu produk ketika ada perubahan pada harga atau pendapatan diatur dalam ekonomi mikro. Individu konsumen menjadi fokus utama dalam ekonomi mikro. Perilaku konsumen ini sudah diatur dalam ekonomi mikro. Apabila konsumen tidak belajar ekonomi mikro, tentu akan menemui banyak masalah terkait pemenuhan kebutuhan. Skala prioritas terdapat dalam ekonomi mikro. Banyak individu atau konsumen yang tidak membuat skala prioritas dalam memenuhi kebutuhan sehari-hari. Hal itu berdampak pada kondisi masyarakat yang kurang sejahtera karena mereka tidak membedakan mana kebutuhan yang saat ini dan mana yang bisa ditunda. Selain itu yang lebih parah lagi adalah mereka tidak bisa membedakan kebutuhan dan keinginan yang harus dipenuhi.

Di dalam ilmu ekonomi, konsumsi bermakna membelanjakan kekayaan untuk memenuhi keinginan manusia seperti makan, pakaian, perumahan, barangbarang kebutuhan sehari-hari, pendidikan, kesehatan, kebutuhan pribadi maupun keluarga lainnya, dan sebagainya (Chaudhry, 2012:137). Dalam hal ini konsumsi tidak hanya makanan saja, namun segala yang kita keluarkan termasuk konsumsi. Konsumsi merupakan hal yang penting yang dilakukan oleh setiap orang, sehingga perlunya ilmu pengetahuan agar dapat berkonsumsi secara bijak.

Perilaku konsumsi seseorang pasti berbeda dengan perilaku konsumsi orang lain (Astuti, 2016). Sepeda motor misalnya, ini sangat diperlukan untuk mahasiswa yang jarak tinggalnya jauh dari kampus. Berbeda dengan mahasiswa yang tinggalnya dekat, jalan kaki saja sudah cukup untuk memenuhi kebutuhan ke kampus. Meskipun berbeda, Islam telah mengatur bahwa dalam konsumsi dianjurkan untuk tidak boros dan kikir.

Program Satu Keluarga Satu Sarjana (SKSS) adalah Beastudi mahasiswa berprestasi di kapus negeri yang berasal dari 
Hidayat, et al/Jurnal Ekonomi Syariah Teori dan Terapan Vol. 6 No. 7 Juli 2019: 1462-1475; PENERAPAN PERILAKU KONSUMSI ISLAM PADA PENERIMA BEASISWA SATU KELUARGA SATU SARJANA BADAN AMIL ZAKAT NASIONAL DI JAWA TIMUR (PERSPEKTIF FAHIM KHAN)

berbagai wilayah di Indonesia. Program ini mengutamakan mahasiswa yang berasal dari keluarga tidak mampu yang salah satu anggota keluarga belum memiliki tingkat pendidikan sarjana. Beastudi SKSS membiayai mahasiswa semester pertama samapai lUlus menjadi sarjana. SKSS adalah program beasiswa yang mengutamakan pengabdian kepada masyarakat. Setiap peserta Beastudi SKSS diharapkan akan menjadi sarjana pelopor pemberdayaan masyarakat wilayah masing-masing (baznas.go.id). Peneliti tertarik untuk melakukan penelitian mengenai konsumsi Islam pada SKSS BAZNAS karena salah satu kriteria untuk bisa diterima dalam beasiswa SKSS BAZNAS adalah bersedia untuk menjalani ikatan dinas menjadi relawan BAZNAS. Sebelum mejalani menjadi relawan BAZNAS atau Amil BAZNAS tersebut, haruslah para mahasiswa penerima beasiswa mampu untuk mengelola konsumsinya sendiri. Harapaanya adalah setelah diperolehnya ilmu dan pelatihan tentang zakat, penerima beasiswa SKSS BAZNAS ini mampu memahami tentang konsumsi dan diharapkan dapat mengedukasi kepada muzakki atau calon muzakki dalam mengelola konsumsinya sendiri.

Berdasarkan penjelasan diatas maka peneliti ingin membahas tentang perilaku konsumsi Islam perspektif Fahim Khan pada penerima beasiswa SKSS BAZNAS di Jawa Timur. Konsumsi yang dilakukan sudah sesuai dengan syariah atau belum. Dalam Islam terdapat aturan terkait konsumsi, sehingga sebagai umat Islam dan kader BAZNAS perlu memperhatikan hal tersebut.

Fahim Khan merupakan pemikir Muslim yang lahir di India pada tahun 1946. Fahim Khan termasuk jajaran ahli ekonomi Islam kontemporer yang di samping memiliki kapabilitas yang handal secara akademis juga memiliki pengalaman praktis dalam pengembangan ekonomi Islam. Dengan gelar Master dalam ekonomi politik dan statistika serta Ph.D dibidang ekonomi, beliau telah memiliki 39 tahun pengelaman dalam bidang kebijakan ekonomi dan perencanaan, dalam mengajar dan pelatihan, pengembangan kapasitas kelembagaan, dan juga penelitian serta konsultan.

\section{Rumusan Masalah}

Berdasarkan latar belakang yang telah diuraikan diatas, maka peneliti menarik rumusan masalah penelitian "Bagaimana penerapan perilaku konsumsi Islam perspektif Fahim Khan pada penerima beasiswa SKSS BAZNAS Jawa Timur?"

\section{Tujuan Penelitian}

Berdasarkan rumusan masalah diatas, maka tujuan dari penelitian ini adalah untuk mengetahui penerapan perilaku konsumsi Islam perspektif Fahim Khan pada penerima beasiswa SKSS BAZNAS Jawa Timur.

\section{LANDASAN TEORI}

\section{Pengertian Konsumsi}

Konsumsi adalah penggunaan barang-barang dan jasa-jasa yang secara langsung akan memenuhi kebutuhan manusia, sedangkan pelakunya yakni 
Hidayat, et al/Jurnal Ekonomi Syariah Teori dan Terapan Vol. 6 No. 7 Juli 2019: 1462-1475; PENERAPAN PERILAKU KONSUMSI ISLAM PADA PENERIMA BEASISWA SATU KELUARGA SATU SARJANA BADAN AMIL ZAKAT NASIONAL DI JAWA TIMUR (PERSPEKTIF FAHIM KHAN)

individu dan rumah tangga disebut sebagai konsumen (Rosyidi, 2006). Menurut (Eachern, 2001:490) konsumsi mempunyai pengertian yang lebih luas yaitu seluruh pembelian barang dan jasa akhir yang sudah siap dikonsumsi oleh rumah tangga untuk memenuhi kebutuhan. Menurut (Sumar'in,2013:85) konsumsi adalah bentuk perilaku ekonomi yang asasi dalam kehidupan manusia. Pada ilmu ekonomi, konsumsi adalah setiap perilaku seseorang untuk menggunakan dan memanfaatkan barang atau jasa untuk memenuhi kebutuhan hidup.

Konsumsi menurut para peneliti ekonomi Islam tidak berbeda dengan definisi tersebut, akan tetapi kesamaan definisi tidak berarti kesamaan dalam semua yang meliputinya. Sebab, barang atau jasa yang dipergunakan dalam memenuhi kebutuhan seseorang Muslim harus halal dan sesuai syariah. Demikian pula tujuan konsumsi bagi konsumen Muslim seyogiyanya berbeda dengan tujuan konsumsi konsumen non-Muslim (Sumar'in, 2013). Terdapat dua sasaran pengeluaran harta, pertama, diri sendiri dan keluarga. Kedua, pengeluaran fi sabilillah melalui shadaqah, zakat, infak, dan silaturahim (Qardhawi, 1997). Allah memerintahkan kepada manusia untuk memenuhi kebutuhan sendiri dan orang lain. Perintah tersebut tertulis dalam Al-Qur'an.

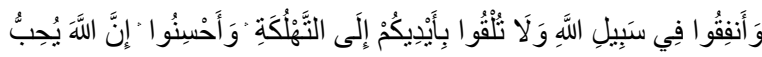

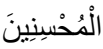

Wa anfiqu fi sabilillahi wa la tulqu bi aidikum ilat-tahlukati wa ahsinu, innallaha yuhibulmuhsinin

Artinya: Dan belanjakanlah (harta bendamu) di jalan Allah, dan janganlah kamu menjatuhkan dirimu sendiri kedalam kebinasaan, dan berbuat baiklah karena sesungguhnya Allah menyukai orang-orang yang berbuat baik (QS Al Baqarah:195).

\section{Tujuan Konsumsi}

Tujuan konsumsi seseorang dalam Islam antara lain (Hakim:89-92):

1. Untuk mengharap ridha Allah SWT.

2. Untuk mewujudkan kerjasama antaranggota masyarakat dan tersedianya jaminan sosial.

3. Untuk menumbuhkan rasa tanggung jawab individu terhadap kemakmuran. diri, keluarga dan masyarakat sebagai bagian aktivitas dan dinamisasi ekonomi.

4. Untuk meminimalisasi pemerasan dengan menggali sumber-sumber nafkah.

5. Supaya negara melakukan kewajibannya terhadap warga negara yang masih tergolong miskin.

\section{KEBUTUHAN DAN KEINGINAN}

Siddiqi (1979) menjelaskan kunci pemeliharaan dari lima tujuan dasar terletak pada penyediaan tingkat pertama, yaitu kebutuhan seperti makanan, pakaian, dan perumahan. Namun demikian, Ghazali menyadari bahwa kebutuhan-kebuthan dasar demikian cenderung fleksibel mengikuti waktu dan tempat dan dapat mencakup bahkan kebutuhan - kebutuhan sosiopsikologis. Kelompok kebutuhan kedua terdiri dari semua kegiatan dan hal-hal yang 
Hidayat, et al/Jurnal Ekonomi Syariah Teori dan Terapan Vol. 6 No. 7 Juli 2019: 1462-1475; PENERAPAN PERILAKU KONSUMSI ISLAM PADA PENERIMA BEASISWA SATU KELUARGA SATU SARJANA BADAN AMIL ZAKAT NASIONAL DI JAWA TIMUR (PERSPEKTIF FAHIM KHAN)

tidak vital bagi limafondasi tersebut, tetapi dibutuhkan untuk menghilangkan rintangan dan kesukaran dalam hidup. Kelompok ketiga mencakup kegiatan-kegiatan dan hal-hal yang lebih jauh dari sekadar kenyamanan saja; meliputi hal-hal yang melengkapi, menerangi atau menghiasi hidup.

Memenuhi kebutuhan dan bukan memenuhi kepuasan atau keinginan yaitu tujuan dari aktivitas ekonomi islam, dan usaha untuk pencapaian tujuan tersebut merupakan sala satu kewajiban dalam agama. Siddiqi (1979) menyatakan bahwa tujuan aktivitas ekonomi Islam yang sempurna menurut Islam antara lain:

1. Memenuhi kebutuhan hidup seseorang secara sederhana

2. Memenuhi kebutuhan keluarga

3. Memenuhi kebutuhan jangka panjang

4. Menyediakan kebutuhan keluarga yang ditinggalkan

5. Memberikan bantuan sosial dan sumbangan menurut jalan Allah.

Beberapa pandangan tersebut mempunyai satu tujuan, yaitu untuk mewujudkan kemaslahatan dalam kehidupan masyarakat.

Khan (2014) membagi tingkatan kebutuhan menjadi tiga, yaitu:

1. Tingkat dimana lima unsur mendasar itu sedikit saja terlindungi

2. Tingkat dimana perlindungan terhadap lima unsir mendasar itu dilengkapi dan dikuatkan
3. Tingkaat dimana kelima unsur mendasar tersebut tidak saja terjamin melainkan juga diperbaiki dan diperindah

\section{KONSUMSI PERSPEKTIF FAHIM KHAN}

\section{Konsumsi Dunia Akhirat}

Menurut (Khan, 2014) berapa banyak pendapat yang dikeluarkan untuk kebutuhan duniawi dan berapa banyak untuk jalan Allah (infaq fi sabilillah). Tindakan yang dapat dilakukan mungkin dari tipe pertama atau kedua, tergantung pada niat pelakunya. Hanya saja, dalam konteks ini, yang kita maksud dengan 'pengeluaran di jalan Allah' adalah pengeluaran yang bukan untuk kepentingan dunia orang yang bersangkutan. Dalam kenyataannya, konsumen mempunyai dua keranjang, yaitu keranjang $X$ dan $Y$. Keranjang $X$ berisi pengeluaran untuk memenuhi kebutuhan duniawi, sedangkan keranjang $Y$ berisi pengeluaran di jalan Allah.

Y

jalan

Allah

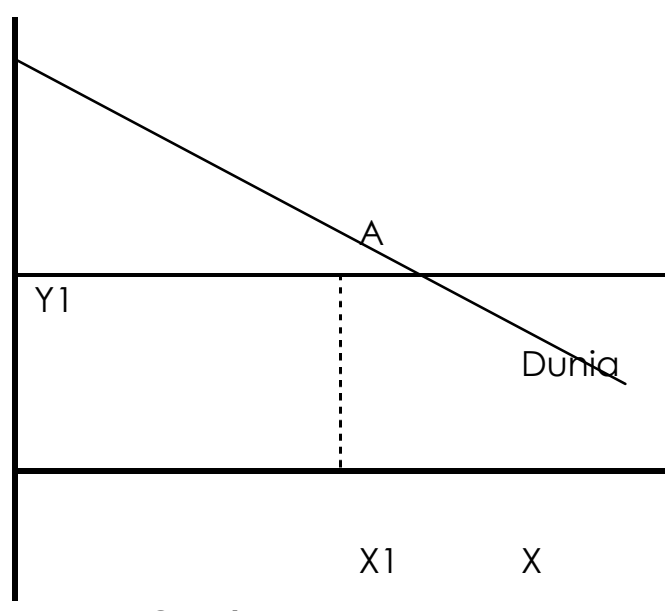

Gambar 1.

\section{Konsumsi Dunia Akhirat}

Imbalan bagi setiap pengeluaran pada keranjang $Y$ lebih tinggi daripada 
Hidayat, et al/Jurnal Ekonomi Syariah Teori dan Terapan Vol. 6 No. 7 Juli 2019: 1462-1475; PENERAPAN PERILAKU KONSUMSI ISLAM PADA PENERIMA BEASISWA SATU KELUARGA SATU SARJANA BADAN AMIL ZAKAT NASIONAL DI JAWA TIMUR (PERSPEKTIF FAHIM KHAN)

kepuasan duniawi yang dapat ia peroleh dari pengeluaran yang sama pada keranjang $X$. Meski demikian, dia tidak dapat mulai dari A lalu menghabiskan seluruh anggarannya pada keranjang $Y$ karena ada nilai minimum $X$ yang harus dipenuhi untuk kebutuhan hidup.

\section{Konsumsi Sekarang dan Nanti}

Menabung untuk keperluan konsumsi di masa mendatang jelas diperbolehkan dan diinginkan. Ajaran Nabi Muhammad Saw. bahwa, jika seseorang meninggal, adalah lebih baik meninggalkan keturunan yang berkecukupan daripada yang miskin, menunjukkan bahwa menabung itu dianjurkan. Tetapi, berapa banyak pendapatan yang ditabung dan berapa banyak pula yang dikonsumsi sekarang, sekali lagi merupakan pertanyaan yang tidak memerlukan perilaku memaksimumkan.

The expected rate of return dari tabungan, bukan tingkat bunga, adalah motivasi menabung dalam kerangka Islam. Alasannya jelas. Seorang Muslim harus membayar zakat atas tabungannya. Tabungan akan terkurangi setiap tahun oleh zakat sehingga tujuan menabung jadi tidak tercapai.. dengan keberadaan zakat, tabungan hanya masuk akal jika tabungan itu menghasilkan pendapatan, sehingga zakat dapat dibayar dari tabungan tersebut. Lagi pula, bukan hanya zakat saja yang dibayar dari pendapatan tersebut. Namun juga menolong sesama yang membutuhkan. Demikianlah the expected rate of return tabungan memainkan peran positif dalam menolong tabungan.

Kebutuhan Dharuriyyah, Hajiyyah,

Tahsiniyyat

Kebutuhan dalam Islam

dikategorikan menjadi tiga hal pokok: (Idris, 2015:106-108)

Kebutuhan primer (dharuriyyah), yaitu kebutuhan yang berkaitan dengan hidup-mati seseorang, seperti kebutuhan pada oksigen, makanan, dan minuman. Kebutuhan ini sangat penting untuk manusia sehingga perlu dipenuhi. Ketika memenuhi kebutuhan ini tidak boleh berlebihan.

Kebutuhan sekunder (hajiyyah), yaitu kebutuhan yang diperlukan untuk mengatasi kesulitan, tetapi tidak sampai mengancam kehidupan apabila tidak dipenuhi. Kebutuhan ini guna memudahkan hal-hal yang ada dalam kebutuhan primer. Allah berfirman dalam surat Al-Isra' ayat 66:

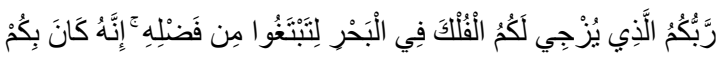

رَحِيمًا

rabbukumu alladzii yuzjii lakumu alfulka fii albahri litabtaghuu min fadhlihi innahu kaana bikum rahiimaan

Artinya: Tuhanmulah yang melayarkan kapal-kapal di lautan untukmu, agar kamu mencari karunia-Nya. Sungguh Dia Maha Penyayang terhadapmu.

Kebutuhan tersier (tahsiniyyah), yaitu kebutuhan yang bersifat aksesoris, pelengkap, dan memberi nilai tambah pada pemenuhan kebuthan primer dan sekunder. Dalam hal ini, Allah berfirman dalam surat 16/An-Nahl ayat 14:

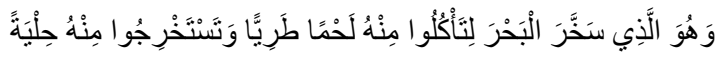

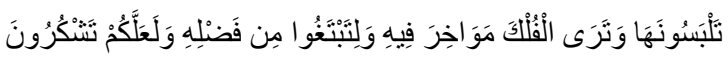


Hidayat, et al/Jurnal Ekonomi Syariah Teori dan Terapan Vol. 6 No. 7 Juli 2019: 1462-1475; PENERAPAN PERILAKU KONSUMSI ISLAM PADA PENERIMA BEASISWA SATU KELUARGA SATU SARJANA BADAN AMIL ZAKAT NASIONAL DI JAWA TIMUR (PERSPEKTIF FAHIM KHAN)

rabbukumu alladzii yuzjii lakumu alfulka fii albahri litabtaghuv min fadhlihi innahu kaana bikum rahiimaan

Artinya: Dan Dialah yang menundukkan lautan (untukmu), agar kamu dapat memakan daging yang segar (ikan) darinya, dan (dari lautan itu) kamu mengeluarkan perhiasan yang kamu pakai. Kamu juga melihat perahu berlayar padanya, dan agar kamu mencari sebagian karunia-Nya, dan agar kamu bersyukur

\section{Subtitusi}

Barang subtitusi adalah barang yang mempunyai hubungan saling menggantikan, jika harga barang dimaksud mengalami kenaikan maka jumlah yang diminta akan barang pengganti justru akan meningkat. Pengaruh subtitusi (substitution effect), jika harga suatu barang naik maka orang akan mencari barang lain yang fungsinya sama, tetapi harganya lebih murah. Sehingga harga barang subtitusi berpengaruh positif terhadap permintaa suatu barang (Ida, 2009).

Mankiw (2008) dalam Christianto (2013) berpendapat bahwa suatu barang yang memiliki barang subtitusi atau barang pengganti akan memiliki elastisitas yang elastis, sedangkan barang yang tidak memiliki barang subtitusi cenderung memiliki elastisitas yang inelastis. Sebab apabila barang tersebut mengalami peningkatan harga dan terdapat banyak barang subtitusi yang harganya dibawah harga barang tersebut, maka permintaan barang tersebut akan mengalami penurunan permintaan yang tajam. Berbeda dengan barang yang tidak memiliki barang subtitusi, hanya mengalami penurunan permintaan yang sedikit karena orang hanya menurunkan permintaan barang tersebut.

\section{Proposisi}

Proposisi dalam penelitian ini adalah penerapan perilaku konsumsi Islam perspektif Fahim Khan pada penerima beasiswa Satu Keluara Satu Sarjana (SKSS) Badan Amil Zakat Nasional di Jawa Timur.

\section{METODE PENELITIAN}

\section{Pendekatan Penelitian}

$$
\text { Peneliti ini menggunakan }
$$

pendekatan kualitatif. Yin (2002:2) mengungkapkan bahwa pendekatan kualitatif adalah pendekatan menggunakan data yang berupa kalimat tertulis atau lisan, peristiwa-peristiwa, pengetahuan atau proyek studi yang bersifat deskriptif. Bachri (2010:3) mengungkapkan bahwa penelitian kualitatif adalah suatu penelitian yang ditujukan untuk mendeskripsikan dan menganalisis fenomena, peristiwa, aktivitas sosial, sikap, kepercayaan, persepsi, pemikiran orang secara individu maupun kelompok.

Moleong (2005:6) menjelaskan bahwa penelitihan kualitatif adalah penelitian yang menghasilkan prosedur analsis yang tidak menggunakan prosedur analisis statistik atau cara kuantifikasi lainnya. Kualitatif lebih kepada pemaparan atau penjabaran atas masalah yang diangkat dalam penelitian.

\section{Ruang Lingkup Penelitian}

Ruang lingkup dalam penelitian ini berdasarkan pada rumusan masalah 
Hidayat, et al/Jurnal Ekonomi Syariah Teori dan Terapan Vol. 6 No. 7 Juli 2019: 1462-1475; PENERAPAN PERILAKU KONSUMSI ISLAM PADA PENERIMA BEASISWA SATU KELUARGA SATU SARJANA BADAN AMIL ZAKAT NASIONAL DI JAWA TIMUR (PERSPEKTIF FAHIM KHAN)

penelitian yang diungkapkan diatas, yaitu Bagaimana penerapan perilaku konsumsi Islam perspektif Fahim Khan pada penerima beasiswa SKSS BAZNAS Jawa Timur. Rumusan masalah tersebut akan menjadi acuan agar isi pembahasan tidak keluar dari topik. Penelitian ini akan menjelaskan tentang penerapan konsumsi Islam pada penerima beasiswa SKSS BAZNAS. Diantara 18 mahasiswa penerima beasiswa SKSS BAZNAS, peneliti akan mengambil informan yang sesuai dengan kriteria informan yang akan di wawancarai. Mahasiswa penerima beasiswa SKSS BAZNAS tersebut terdiri dari 2 kampus di Surabaya, Universitas Airlangga dan Institut Teknologi Sepuluh Nopember. Pemilihan objek penelitian didasarkan atas pertimbangan bahwa:

a. Informan adalah mahasiswa yang masih berstatus kuliah

b. Informan merupakan mahasiswa yang berasal dari luar Kota Surabaya

\section{Jenis dan Suber Data}

Data yang digunakan dalam penelitian kualitatif ini adalah data primer dan sekunder. Data primer adalah data yang diperoleh langsung dari sumber, baik individu atau perorangan dan dokumen (Afifuddin dan Saebani, 2009). Dengan metode wawancara dan observasi maka peneliti dapat menggali informasi yang lebih mendalam pada penerima beasiswa SKSS BAZNAS Jawa Timur dan beberapa informan pendukung. Sedangkan data sekunder menurut (Sugiyono 2005 : 62), data sekunder adalah data yang tidak langsung memberikan data kepada peneliti, misalnya penelitian melalui orang lain atau mencari melalui dokumen.

Sumber data penelitian ini diperoleh dari:

a. Data Primer

Sumber primer adalah sumber data yang langsung memberikan data kepada pengumpul data (Sugioyo, 2012). Dalam penelitian ini, yang menjadi informan adalah penerima beasiswa SKSS BAZNAS Jawa Timur. Adanya informan tambahan akan membuat hasil penelitian ini lebih valid. Data primer sebagai data utama yang diperoleh langsung dari informan yang bersangkutan. Menurut Wangsa dan Ming Kuan (2011:12), "Data primer adalah data utama yang penulis peroleh dari pihak - pihak yang bersangkutan pada perusahaan yang menjadi objek penelitian. Data primer akan didapatkan dengan wawancara mendalam (indepth interview) dan observasi langsung terhadap informan yang dipilih

b. Data Sekunder

Sumber sekunder adalah data yang diperoleh dengan cara membaca, mempelajari, dan memahami melalui media lain yang bersumber dari literatur, buku-buku, serta dokumen perusahaan (Sugioyo, 2012). Data sekunder penelitian ini diperoleh dari arsip data Baznas dan beberapa penelitian sebelumnya.

\section{Teknik keabsahan Data}

Menilai keabsahan data dalam penelitian kualitatif dimulai ketika proses 
Hidayat, et al/Jurnal Ekonomi Syariah Teori dan Terapan Vol. 6 No. 7 Juli 2019: 1462-1475; PENERAPAN PERILAKU KONSUMSI ISLAM PADA PENERIMA BEASISWA SATU KELUARGA SATU SARJANA BADAN AMIL ZAKAT NASIONAL DI JAWA TIMUR (PERSPEKTIF FAHIM KHAN)

pengumpulan data. Pada penelitian ini, peneliti menggunakan teknik triangulasi untuk memeriksa keabsahan data. Ada tiga macam triangulasi. Menurut (Sugiono, 2014) macam-macam triangulasi tersebut yaitu:

a. Triangulasi Sumber

Cara untuk menguji kredibilitas data yaitu dengan mengecek data yang telah diperoleh melalui beberapa sumber. Contohnya, untuk menguji kredibilitas data tentang gaya kepemimpinan seseorang, maka pengumpulan data pengujian data yang telah diperoleh dilakukan ke bawahan yang dipimpin, ke atasan yang menguasai, dan ke rekan kerja yang merupakan kelompok kerjasama.

b. Triangulasi Teknik

Cara menguji kredibilitas data dengan triangulasi teknik yaitu dengan mengecek data kepada sumber yang sama dengan teknik yang berbeda. Misalnya, data diperoleh dengan wawancara, lalu dicek dengan observasi, kuisioner, atau dokumentasi.

c. Triangulasi Waktu

Waktu juga sering memengaruhi kredibilitas data. Data yang dikumpulkan dengan teknik wawancara di pagi hari ketika informan masih segar, belum banyak masalah akan memberikan data yang lebih valid.

Triangulasi yang digunakan pada penelitian ini adalah triangulasi sumber dan teknik. Triangulasi sumber pada penelitian ini dilakukan dengan membandingkan hasil wawancara antar informan. Dalam hal ini peneliti akan membandingkan hasil wawancara informan penerima beasiswa SKSS BAZNAS Jawa Timur, kerabat dekat penerima beasiswa SKSS BAZNAS, dan pengurus harian SKSS BAZNAS Jawa Timur. Membandingkan isi suatu data tersebut guna memperoleh keterkaitan antardata.

Triangulasi teknik yang digunakan adalah mengecek data yang diperoleh dari hasil wawancara dan dibandingkan dengan hasil dari dokumentasi. Hal ini akan membuat hasil penelitian ini lebih valid.

\section{Teknik Analisis Data}

Analisis data menurut Patton dalam Moleong (2012) adalah proses mengatur urutan data, mengorganisasikannya ke dalam suatu pola, kategori, dan satuan uraian dasar. Langkah-langkah analisis data kualitatif oleh Miles dan Hubberman dalam Sugiyono (2012), yang dikelompokkan menjadi tiga langkah dasar yakni:

a. Data Reduction (Reduksi Data)

Reduksi data adalah proses pemilihan, pemusatan perhatian pada penyederhanaan, pengabstrakan, dan transformasi data kasar yang muncul dari catatan-catatan tertulis di lapangan. Selanjutnya peneliti akan mengarahkan, memilih yang sesuai, dan mengorganisir data sehingga diperoleh data-data yang dibutuhkan pada penelitian.

b. Data Display (Penyajian Data)

Penyajian data adalah sekumpulan informasi tersusun dan memberikan kemungkinan adanya penarikan kesimpulan dan pengambilan tindakan berikutnya. Penyajian data dalam 
Hidayat, et al/Jurnal Ekonomi Syariah Teori dan Terapan Vol. 6 No. 7 Juli 2019: 1462-1475; PENERAPAN PERILAKU KONSUMSI ISLAM PADA PENERIMA BEASISWA SATU KELUARGA SATU SARJANA BADAN AMIL ZAKAT NASIONAL DI JAWA TIMUR (PERSPEKTIF FAHIM KHAN)

penelitian ini disajikan dalam bentuk teks naratif, bagan dan tabel yang diperolah dari hasil wawancara pada informan.

c. Data Verification (Verifikasi Data)

Verifikasi data adalah pengambilan kesimpulan dari informasi yang telah tersusun. Kesimpulan awal yang dikemukakan masih bersifat sementara, dan akan berubah apabila tidak didapati bukti-bukti kuat yang mendukung pada saat tahap pengumpulan data selanjutnya. Namun apabila penarikan kesimpulan tahap awal sudah didapati bukti-bukti yang valid, maka kesimpulan yang dikemukakan merupakan kesimpulan yang kredibel. Data yang telah tersaji sebelumnya perlu diverifikasi ulang berdasarkan rumusan masalah penelitian.

IV. HASIL DAN PEMBAHASAN

\section{Pembahasan}

\section{Konsumsi Dunia Akhirat}

Pendapat yang dikeluarkan untuk kebutuhan duniawi dan berapa banyak untuk jalan Allah (infaq fi sabilillah). Tindakan yang dapat dilakukan mungkin dari tipe pertama atau kedua, tergantung pada niat pelakunya. Hanya saja, dalam konteks ini, yang kita maksud dengan 'pengeluaran di jalan Allah' adalah pengeluaran yang bukan untuk kepentingan dunia orang yang bersangkutan (Khan, 2014). Semua informan telah mampu membagi kebutuhan untuk dunia dan jalan Allah dengan baik. Penerapan dalam kehidupan sehari-hari terwujud dengan telah dipenuhinya segala kebutuhan perkuliahan maupun kebutuhan yang lainnya. Selain itu tidak lupa pemenuhan kebutuhan akhirat berupa sedekah, bhakti sosial, infak uang dilakukan ke masjid dan orang yang membutuhkan.

Prinsip konsumsi dunia dan akhirat pada dasarnya adalah prinsip yang bersifat fundamental untuk konsumsi baik memenuhi kebutuhan dunia maupun akhirat. Tahapan ini sangat penting untuk taha berikutnya.

Semua informan memiliki latar belakang yang sama yaitu penerima beasiswa SKSS BAZNAS dan berstatus masih aktif kuliah. Semuanya juga telah memenuhi kebutuhan untuk dunia dan akhirat meskipun ada perbedaan dalam barang yang dikonsumsi. I2INAW merupakan informan yang paling jelas dan detil dalam membedakan konsumsi dunia dan akhiratnya. Pentingnya mengalokasikan kebutuhan untuk dunia maupun akhirat sudah disadari oleh semua informan karena memang informan sudah mendapat pengetahuan hal ini dari sekolah, pondok pesantren, dan kegiatan keagamaan di masyarakat.

Informan pada penelitian ini mengutamakan pendidikan terbukti dengan semua informan yang sedang aktif kuliah dan pendidikan luar kampus untuk menunjang akademik. Tidak hanya itu, pendidikan diluar kampus juga dapat mengembangkan softskill individu. Bahkan I5YS sangat berambisi untuk melanjutkan kuliah S 2 dengan beasiswa LPDP atau menggunakan biaya sendiri dari tabungan yang telah dipersiapkan. Semua anggota beasiswa SKSS BAZNAS juga menerapkan 
Hidayat, et al/Jurnal Ekonomi Syariah Teori dan Terapan Vol. 6 No. 7 Juli 2019: 1462-1475; PENERAPAN PERILAKU KONSUMSI ISLAM PADA PENERIMA BEASISWA SATU KELUARGA SATU SARJANA BADAN AMIL ZAKAT NASIONAL DI JAWA TIMUR (PERSPEKTIF FAHIM KHAN)

kewajiban sebagai mahasiswa yaitu engabdian kepada masyarakat di Kenjeran Surabaya dengan memberikan pengajaran kepada putra putri nelayan selama 6 bulan.

Penerima beasiswa SKSS BAZNAS mengadakan iuran yang penggunaannya untuk acara yang diadakan oleh penerima beasiswa SKSS BAZNAS. Selain itu dana tersebut juga digunakan untuk Qurban berupa kambing yang disalurkan ke masjid. Kegiatan tersebut dilakukan untuk melatih pribadi dalam berqurban.

Semua informan setiap bulan mengalokasikan uangnya untuk bersedekah. Bersedekah berupa uang, barang, maupun makanan. Bahkan I5YS mengalokasikan dirinya dalam kegiatan sosial di Yayasan Embun Sosial Surabaya.

Semua informan pada dasarnya sudah mengetahui pengetahuan tentang agama Islam yang tinggi. Sholat merupakan hal utamayang mereka prioritaskan. Bahkan IIINAW mewajibkan para penghuni kontrakan untuk sholat berjamaah. I4NAL berpendapat bahwa sholat khusyu' akan mendapatkan ketenangan hati dan segala urusan dilancarkan. Semua informan pada penelitian ini tempat tinggalnya dekat dengan masjid atau mushola, sehingga sangat mudah akses untuk sholat berjamaah. I3MSI mendahulukan sholat ketika waktunya berbenturan dengan jadwal kuliah. Semua informan membeli perlengkapan ibadah seperti: sarung, mukena, kopyan baju koko dan lain sebagainyaitu setahun sekali ketika Hari Raya.

\section{Konsumsi Sekarang dan Nanti}

Menabung untuk keperluan konsumsi di masa mendatang jelas diperbolehkan dan diinginkan. Ajaran Nabi Muhammad Saw. bahwa, jika seseorang meninggal, adalah lebih baik meninggalkan keturunan yang berkecukupan daripada yang miskin, menunjukkan bahwa menabung itu dianjurkan (Khan, 2014). Infroman telah mampu mengalokasikan beberapa vangnya untuk ditabung. Penggunaan tabungan tersebut mayoritas untuk jagajaga apabila dikemudian hari ada kebutuhan yang mendadak. Namun I5YS menggunakan tabungan tersebut untuk melanjutkan kuliah $S$ 2. Informan tidak menggunakan tabungannya untuk investasi karena untuk saat ini mereka belum sampai ke tahap itu.

Seluruh informan sadar akan pentingnya menabung. Semua informan menabung di bank dan ada yang punya tabungan sendiri di rumah. Namun I4NAL menabung di bank konvensional karena tuntutan pekerjaan di salah satu ojek online. Setiap bulannya informan mengalokasikan vangnya untuk ditabung sebesar Rp 100.000 sampai Rp 300.000.

Tempat tinggal merupakan kebutuhan yang enting untuk semua informan karena seluruh informan merupakan mahasiswa perantauan yang berasal dari luar kota Surabaya. Saat ini pertimbangan bagi seluruh informan dalam mencari tempat tinggal adalah harganya yang murah. Hal tersebut wajar karena semua informan masih mahasiswa. Namun 
Hidayat, et al/Jurnal Ekonomi Syariah Teori dan Terapan Vol. 6 No. 7 Juli 2019: 1462-1475; PENERAPAN PERILAKU KONSUMSI ISLAM PADA PENERIMA BEASISWA SATU KELUARGA SATU SARJANA BADAN AMIL ZAKAT NASIONAL DI JAWA TIMUR (PERSPEKTIF FAHIM KHAN)

IIINAW mencari tempat tinggal tidak hanya faktor harga yang murah, namun juga kondisi penghuni kontrakannya. Kontrakan IIINAW saat ini adalah kontrakan sholehah.

Makanan juga sangat penting dan diperhatikan oleh semua informan. Mayoritas pertimbangan dalam memilih makanan adalah halal, murah, dan sehat. I2FCY dan IIINAW lebih memilih membawa makanan dari tempat tinggal daripada harus beli diluar yang belum tentu higienis. Terlebih IIINAW punya alergi terhadap beberapa makanan. Sedangkan I3MSI dan I4NAL lebih memilih membeli makanan diluar dengan pertimbangan murah dan halal. Sedangkan I5YS cenderung membeli makanan apa yang diinginkan, namun juga menyesuaikan dengan kondisi keuangan.

\section{Konsumsi Dharuriyyah, Hajiyyah, Tahsiniyyah}

Prinsip dasarnya amatlah sederhana.

Sumber daya haruslah pertama kali dialokasikan untuk hal terpenting, yakni dharuriyyat. Jika sesudah itu konsumen masih memiliki sisa sumber daya, dia dapat melanjutkan ke barang-barang yang dapat menjadi komplemen bagi dharuriyyat itu, yakni hajiyyat. Jika masih pula ada sisa sumber daya, maka sisa itu dapat dialokasikan kepada kegiatan memperbaiki atau memperindah, yakni tahsiniyyat (Khan, 2014). Setiap orang mempunyai kebutuhan yang berbeda meskipun dengan tujuan yang sama yaitu terpenuhinya kebutuhan manusia. Informan telah mampu memilih dan memilah kebutuhannya dengan baik. Informan yang berstatus sebagai mahasiswa ini tidak mempunyai kebutuhan yang kompleks. Kebanyakan kebutuhan informan adalah terkait dengan kebutuhan harian seperti makan, tempat tingga, pakaian, dan kegiatan perkuliahan. Namun tidak lupa juga kebutuhan akan hiburan yang sudah cukup dipenuhi oleh informan.

Secara umum semua informan telah mampu memenuhi kebutuhan primer dan sekunder dengan baik. Mereka juga bisa membedakan manakah konsumsi untuk duniawi dan akhirat. Namun untuk tersier, I2FCY, masih dalam tahapan primer dan sekunder karena prinsip hidup sederhana yang dia terapkan. I3MSI telah memenuhi kebutuhan primer meskipun ada beberapa kebutuhan yang seharusnya belum waktunya untuk dipenuhi namun sudah dipenuhi. Contoh dalam hal ini adalah I3MSI membeli raket badminton yang asli dengan harga mahal padahal sudah mempunyai raket dengan kondisi yang tergolong masih bagus.

\section{Konsumsi Substitusi}

Ida (2009) mengartikan barang subtitusi adalah barang yang mempunyai hubungan saling menggantikan, jika harga barang dimaksud mengalami kenaikan maka jumlah yang diminta akan barang pengganti justru akan meningkat. Mankiw (2008) dalam Christianto (2013) berpendapat semakin luas ruang lingkupnya maka semakin inelastis barang tersebut karena tidak ada barang subtitusinya. Sebalinya, semakin sempit atau kecil ruang lingkupnya maka semakin elastis barang tersebut. Pemilihan barang subtitusi atas kebutuhan yang akan dipenuhi 
Hidayat, et al/Jurnal Ekonomi Syariah Teori dan Terapan Vol. 6 No. 7 Juli 2019: 1462-1475; PENERAPAN PERILAKU KONSUMSI ISLAM PADA PENERIMA BEASISWA SATU KELUARGA SATU SARJANA BADAN AMIL ZAKAT NASIONAL DI JAWA TIMUR (PERSPEKTIF FAHIM KHAN)

tergolong kecil. Mayoritas mereka tetap mengusahkan untuk memenuhi apapun yang sedang mereka butuhkan. I2FCY bahkan akan meminjam barang tersebut ke orang lain. Namun I4NAL masih bisa menyadari bahwa jika barang yang dibutuhkan tidak ada maka diganti dengan barangyang lain dengan fubnsi yang sama. Dalam hal ini I4NAL memberi contoh ketia dia membeli sepatu dengan merek tertentu dan tidak ada, kemudian I4NAL membeli sepatu dengan fungsi yang sama namun merek berbeda.

\section{KETERBATASAN PENELITIAN}

Penelitian ini meneliti tentang penerapan perilaku konsumsi Islam pada penerima beasiswa SKSS BAZNAS di Jawa Timur. Peneliti mengalami kesulitan dalam mendapatkan data pendapatan diluar dari beasiswa SKSS BAZNAS karena informan sangat tertutup dengan hal tersebut. Oleh karena itu peneliti melakukan asumsi-asumsi terkait pendapatan informan yang berasal dari luar beasiswa SKSS BAZNAS dengan cara pengamatan analisa terhadap informan.

\section{SIMPULAN}

1. Tingkat pemahaman penerima beasiswa SKSS BAZNAS tentang konsumsi Islam sangat tinggi karena sebelumnya sudah mendapat wawasan dari sekolah, pondok pesantren, dan kegiatan keagamaan di masyarakat. Seluruh informan merupakan individu yang aktif dalam belajar ilmu agama baik secara formal maupun informal.
2. Secara keseluruhan informan telah menerapkan prinsip konsumsi Islam perspektif Fahim Khan dengan baik. Hal ini dikarenakan pengetahuan tentang konsumsi Islam yang telah didapatkan sebelumnya dan kesadaran pribadi untuk menerapkan pengetahuan tersebut. Semua prinsip telah diterapkan oleh penerima beasiswa SKSS BAZNAS, namun terkait barang subtitut beberapa informan tidak melaksanakannya.

3. Konsumsi dunia dan akhirat merupakan prinsip dasar dalam teori ini. Informan telah mampu membedakan dan menerapkan prinsip tersebut dengan baik. Oleh karena itu, seluruh informan dapat dikatakan telah menerapkan prinsip konsumsi Islam dengan cukup baik.

\section{DAFTAR PUSTAKA}

Afifuddin dan Beni Ahmad Saebani. 2009. Metodologi penelitian kualitatif. Bandung: Pustaka Setia.

Arif, M Nur Rianto Al. 2015. Pengantar Ekonomi syariah teori dan praktik. Bandung: Pustaka Setia.

Astuti, Rika Pristian Fitri. 2016. Pengaruh Status Sosial Ekonomi Orang Tua, Literasi Ekonomi dan Life Style Terhadap Perilaku Konsumsi Mahasiswa Jurusan pendidikan Ekonomi IKIP PGRI Bojonegoro. Bojonegoro: Fakultas Pendidikan IImu Pengetahuan Sosial. Jurnal Edutama. Vol 3, no. 2 Juli 2016

Bachri, Bachtiar S. 2010. Meyakinkan Validitas Data Melalui Triangulasi Pada Penelitian Kualitatif. Universitas 
Hidayat, et al/Jurnal Ekonomi Syariah Teori dan Terapan Vol. 6 No. 7 Juli 2019: 1462-1475; PENERAPAN PERILAKU KONSUMSI ISLAM PADA PENERIMA BEASISWA SATU KELUARGA SATU SARJANA BADAN AMIL ZAKAT NASIONAL DI JAWA TIMUR (PERSPEKTIF FAHIM KHAN)

Negeri Surabaya. Vol. 10, No. 1, hal 46-61.

Baidhowi, Bagus dan Irham Zaki. 2014. Implementasi konsumsi Islam Pada Pengajar Pondok Pesantren (Studi Kasus Pengajar Pondok Pesantren Aqobah Kecamatan Diwek Kabupaten Jombang). Universitas Airlangga. Vol. 1, No. 9.

Chan, Arianis. 2010. Pengaruh Ekuitas Merek Terhadap Proses Keputusan Pembelian Konsumen:Sstudi Kasus Bank Muamalat Indonesia Cabang Bandung. Universitas Padjajaran. Jabv6n1.tex

Fauzia, Ika Yunia dan Abdul Kadir Riyadi. 2014. Prinsip Dasar Ekonomi Islam perspektif Maqashid Syariyyah. Jakarta: Kencana

Ida, N. 2009. Pengaruh Ekonomi Mikro. Universitas Muhammadiah Malang Press. Malang

Khan, M Fahim. 2014. Esai-Esai Ekonomi Islam. Jakarta: RajaGrafindo Persada

Moleong, Lexy J. 2005. Metode Penelitian Kualitatif. Bandung: Remaja Rosdakarya.

Panjaitan, Poopy. 2017. Pengaruh Social Media terhadap Produktifitas Kerja Generasi Millenial. Malang: Jurnal Administrasi Bisnis

Pujiyono, Arief. 2006. Teori Konsumsi Islam. Jurnal Dinamika Pembangunan. III (2) : 196-207.

Rosyidi, Suherman. 2006. Pengantar Teori Ekonomi. Jakarta: Raja Grafindo Persada
Shihab, M. Quraish. 2004. Tafsir al-Mishbah: Pesan, Kesan dan Keserasian alQur'an. Jakarta: Lentera Hati. volume 1, cetakan. Ke 2 .

Siddiqi, Muhammad Nejatullah. 2004. Kegiatan Ekonomi dalam Islam. Jakarta: PT. Bumi Aksara

Sitepu, Novi Indriyani. 2016. Perilaku Konsumsi Islam Di Indonesia. Universitas Syiah Kuala Banda Aceh. Vol. 2, No. 1

Sugiyono. 2014. Memahami Penelitian Kualitatif. Bandung: Alfabeta.

Sumar'in. 2013. Ekonomilslam: Sebuah Pendekatan Ekonomi Mikro Perspektif Islam. Yogyakarta: Graha IImu

Suwiknyo, Dwi. 2010. Kompilasi Tafsir AyatAyat Ekonomi Islam. Yogyakarta: Pustaka Pelajar.

Yin, Robert K. 2003. Studi Kasus (desain dan metode). Jakarta: PT Raja Grafindo Persada.

Yin, Robert K. 2015. Studi Kasus: Desain dan Metode. Jakarta: PT Raja Grafindo 